Bolm. Zool., Univ. S. Paulo

6: 157-176, 1983

\title{
DESENVOLVIMENTO PÓS-EMBRIONARIO DE PAGURISTES TORTUGAE SCHMITT, 1933 (DECAPODA, DIOGENIDAE), EM LABORATÓRIO
}

\author{
Nilton José Hebling \\ Maria Lúcia Negreiros-Fransozo \\ Departamento de Zoologia \\ Instituto de Biociências \\ UNESP - Campus de Rio Claro \\ (Recebido em 17.07.1980)
}

\section{RESUMO}

Através de fêmeas ovigeras de Paguristes tortugae Schmitt, 1933, coletadas no litoral Norte do Estado de São Paulo, Brasil, estudou-se a metamorfose, em laboratório, com ênfase especial na morfolcgia externa de cada um dos estágios larvais. Ilustraçōes e descriçōes detalhadas são apresentadas para mostrar a sequência das mudanas que ocorrem no decorrer do desenvolvimento.

Os experimentos foram efetuados em sala climática com temperatura de $25^{\circ} \mathrm{C}$, utilizando-se água do mar com salinidade constante de $35^{\circ} / 00$. As larvas foram mantidas individualmente e o alimento oferecido consistiu de náuplius de Artemia salina.

O desenvolvimento pós-embrionário de $\mathbf{P}$. tortugae compreende três estágios na fase de zoea e um na fase de megalopa envolvendo treze ou quatorze dias de duração.

$\mathbf{A}$ análise comparativa da metamorfose de $\mathbf{P}$. tortugae com as demais espécies da familia Dicgenidae, evidencia uma grande semelhança com Paguristes spinipes Milne-Edwards, 1880, que também ocorre no Brasil e que foi estudada por Provenzano (1978). As principais diferenças morfológicas entre os estágios de zoea e megalopa, destas duas espécies, são também apresentadas.

\section{ABSTRACT}

The larval stages of Paguristes tortugae Schmitt, 1933, were studied in the laboratory, from eggs of ovigerous females collected at northern coast of São Paulo State, with special regard to external morphology. The sequency of the changes during the development are detaily described and shown in figures.

The study was conduced in a climatic room at $25^{\circ} \mathrm{C}$, and sea water of $35^{\circ} / 00$ salinity. Each larvae was kept in an individual container and fed on nauplii of Artemia salina.

The post-embryonic development of $\mathbf{P}$. tortugac comprises three stages of zoea and one of megalopa and takes thirteen to fourteen days in all.

A comparative review of the development of $\mathbf{P}$. tortugae with other species of the family Diogenidae has revealed that this species is very similar to $\mathbf{P}$. spinipes Milne-Edwards, 1880 which also occurs in Brazilian coast. The main differences between these two species larvae are presented. 


\section{INTRODUÇAO}

Entre as 36 espécies brasileiras de Paguridae e Diogenidae relacionadas por Coelho \& Ramos (1972), somente cinco, que também ocorrem em outros países, possuem a descrição do desenvolvimento pós-embrionário publicada: - Calcinus tibicen (Herbst, 1791): Petrochirus diogenes (Linnaeus, 1758); Paguristes spinipes Milne-Edwards, 1880; Pagurus exilis (Benedict, 1892); Clibanarius vittatus (Bosc, 1802) estudadas respectivamente por Provenzano (1962, 1968 e 1978), Scelzo \& Boschi (1969) e Lang \& Young (1977).

Mais recentemente, Brossi-Garcia (1979) estudou mais duas espécies brasileiras, Clibanarius antillensis Stimpson, 1859 e Pagurus criniticornis Dana, 1852.

O gênero Paguristes é o mais numeroso da familia Diogenidae com cerca de uma centena de espécies distribuídas por todos os mares tropicais e subtropicais. Contudo, apenas seis espécies possuem descriçōes à respeito do desenvolvimento pós-embrionário: - P. turgidus (Stimpson), P. oculatus (Fabricius) P. abbreviatus Dechancé, P. sericeus Mílne-Edwards, P. digitalis (Stimpson) e P. spinipes Milne-Edwards que foram estudadas respectivamente, por Hart (1937), Pike \& Williamson (1960), Dechancé (1963), Rice \& Provenzano (1965), Kurata (1968) e Provenzano (1978).

O propósito deste trabalho é descrever com especial destaque na morfologia externa, o desenvolvimento pós-embrionário de $\mathbf{P}$. tortugae, baseado em espécimes criados em laboratório e analisar os intervalos de tempo entre as ecdises sucessivas, comparativamente com os das espécies mais afins, encontradas na bibliografia.

Além disso, com as ilustrações e descrições detalhadas de caaa estágio larval são fornecidos subsídios para futuras especulações filogenéticas, pois segundo Hart 1937, Gurney (1942), Macdonald, Pike \& Williamson (1957) e Kaestner (1970), a ordem Decapoda necessita de uma revisão sistemática e muita importância deve ser dada aos caracteres larvais para se chegar a uma condição satisfatória.

\section{MATERIAL E METODOS}

As coletas de Paguristes tortugae Schmitt, 1933 foram efetuadas nas praias dos municípios de São Sebastião $\left(23^{\circ} 49^{\prime}\right.$ 'S e $\left.45^{\circ} 24^{\prime} \mathrm{W}\right)$ e Uba-

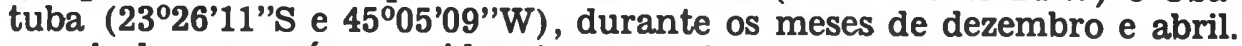

As larvas recém-nascidas (zoeas I) foram individualizadas em placas de Petri de $10 \mathrm{ml}$ e outras, em número de 20, agrupadas em placas controle contendo $80 \mathrm{ml}$ de água.

Como alimento, para cada zoea, foram oferecidos cerca de 15 náuplius recém-nascidos de Artemia salina, introduzidos diariamente nas placas, após a troca de água. Para as megalopas, além de Artemia, ofereceu-se carne de peixe.

Realizou-se 13 experimentos em câmara climática com temperatura de $25^{\circ} \mathrm{C}$, utilizando-se água do mar com salinidade constante de $35 \%$ oo. 
Larvas de cada estágio foram fixadas e conservadas em uma mistura de álcool etílico $70 \%$ e glicerina na proporção de 1:1 e as exúvias foram conservadas em glicerina.

O número de larvas utilizadas para as descrições variou entre 5 e 10, de cada estágio.

As ilustraçōes e medidas foram realizadas com auxilio de um microscópio óptico comum, provido de ocular micrométrica.

\section{RESULTADOS}

O desenvolvimento pós-embrionário de $\mathbf{P}$. tortugae é constituído por três estágios de zoea e um de megalopa.

A fase de zoea envolveu um período de 4 dias, com a obtenção de 38 megalopas. O primeiro e o segundo estágios de zoea tiveram duração de um dia e o terceiro de dois.

A megalopa teve uma duração de 9 ou 10 dias, após a qual mudou para o primeiro estágio juvenil.

Não se constatou estágio de pré-zoea para esta espécie.

Independentemente do estágio em que se encontram e do número de náuplius oferecidos, as zoeas não se alimentam. As megalopas aceitam carne de peixe como alimento.

ZOEA I (Fig. 1-I a 11-I)

A carapaça possui forma geral arredondada, com um pequeno par de espinhos ântero-laterais. $O$ rostro não alcança as extremidades distais das cerdas antenais. Os olhos são sésseis. O $2 .^{\circ}, 3 .^{\circ}, 4 .^{\circ}$ e $5 .^{\circ}$ segmentos abdominais apresentam na região mediana dorsal, um espinho proeminente. $O 5 .^{\circ}$ segmento abdominal apresenta ainda um par de espinhos póstero-laterais. $O$ 6. ${ }^{\circ}$ segmento é fundido ao telso. O telso (Fig. 3-I) apresenta o bordo distal convexo com um entalhe mediano que $o$ divide em duas partes simétricas providas, cada uma, de 7 processos terminais que lhe conferem a fórmula $7+7$.

Antênula (Fig. 4-I) unirreme, não segmentada, ccm 3 estetos e 3 cerdas plumosas na extremidade distal e 1 longa cerda plumosa na extremidade subdistal.

Antena (Fig. 5-I) com exopodito bem desenvolvido, provido de 11 ou 12 cerdas plumosas, 1 cerda simples e uma fileira de pequenas cerdas simples na margem interna. O endopodito é menor que o exopodito, com 3 cerdas plumosas. O protopodito possui 1 pequeno espinho plumoso, na região mediana.

Mandíbula (Fig. 6-I) com o processo incisivo constituído por uma região pontiaguda, com alguns dentes cônicos e o processo molar por numerosos dentes cônicos de vários tamanhos. Năo apresenta palpo mandibular.

Maxílula (Fig. 7-I) com endopodito trisegmentado provido de 1 cerda simples no $2 .^{\circ}$ segmento e 3 no $3 .^{\circ}$. Endito coxal com 5 cerdas plumosas.

Maxila (Fig. 8-I) com exopodito provido de 5 cerdas plumasas na margem externa e uma fileira de cerdas simples na interna. Endopo- 
dito com um total de 8 cerdas simples. $O$ endito basal possui o lobo distal provido de 3 cerdas plumosas e pequenas cerdas simples e o lobo proximal com 4 cerdas plumosas. O endito coxal possui 3 cerdas plumosas no lobo distal, e 1 cerda plumosa e 3 espinhos no lobo proximal.

Primeiro Maxilípede (Fig. 9-I) com basipodito provido de 7 cerdas plumosas marginais. O endopodito sustenta, respectivamente, 1, 2, 1, 2 e 5 cerdas plumosas, na face interna, do segmento proximal para o distal, além de finas cerdas simples na margem externa do $2 .^{\circ}, 3^{\circ} \mathrm{e}$ 4..$^{\circ}$ segmentos. $O$ exopodito apresenta 4 longas cerdas plumosas no segmento distal.

Segundo Maxilípede (Fig. 10-I) com basipodito provido de 8 cerdas plumosas e endopodito com, respectivamente, $3,3,3$ e 5 cerdas plumosas, na face interna, do segmento proximal para o distal, além de finas cerdas simples na margem externa do $2 .^{\circ}$ e $3 .^{\circ}$ segmentos. $O$ exopodito apresenta 4 cerdas plumosas terminais.

Terceiro Maxilipede (Fig. 11-I) pouco desenvolvido, limitado a duas protuberâncias lisas que correspondem aos rudimentos do exopodito e endopodito.

\section{ZOEA II (Figs. 1-II a 11-II)}

A carapaça apresenta uma forma sub-retangular, com um pequeno par de espinhos ântero-laterais. Comparativamente com a zoea I, o rostro sofre uma pequena diminuição no comprimento e os olhos tornam-se ligeiramente pedunculados. $06^{\circ}$ somito abdominal individualiza-se, articulando-se ao telso. Os demais segmentos abdominais apresentam os mesmos espinhos que ocorrem na zoea I, mas no $2^{\circ}, 3 .^{\circ}, 4^{\circ}$ e 5..$^{\circ}$ segmentos surgem os primeiros rudimentos de pleópodos. A fórmula do telso é $8+8$, pela adição de um par de processos na região mediana (Fig. 3-II).

Antênula (Fig. 4-II) birreme e segmentada. O pedúnculo apresenta 3 cerdas simples na margem distal. O endopodito possui 1 longa cerda plumosa distal. $O$ exopodito apresenta 3 estetos, 3 cerdas plumosas e 2 cerdas simples.

Antena (Fig. 5-II) com exopodito provido de 11 cerdas plumosas. Endopodito com aproximadamente o mesmo comprimento do exopodito provido de 3 cerdas em sua região distal. Protopodito com 1 espinho plumoso na região mediana e 1 espinho na margem distal externa.

Mandíbula (Fig. 6-II) com os processos incisivo e molar semelhantes ao do estágio anterior. Surgem os rudimentos do palpo mandibular.

Maxílula (Fig. 7-II) com o endopodito provido de leves traços de segmentação, 2 cerdas simples e 1 pequeno espinho na região distal. $O$ endito basal apresenta 4 espinhos denteados e o endito coxal 5 cerdas plumosas.

Maxila (Fig. 8-II) com 7 cerdas plumosas marginais, no exopodito. Endopodito com 8 cerdas simples. Endito basal com 3 cerdas plumosas em cada lobo. Endito coxal com 3 cerdas plumosas no lobo distal, 3 espinhos e 1 cerda plumosa no lobo proximal.

Primeiro Maxilípede (Fig. 9-II) com basipodito provido de 7 cerdas plumosas marginals. Endopcdito com respectivamente, 2, 1, 0, 3 e 
5 cerdas plumosas, na face interna, do segmento proximal para o distal. As cerdas simples que existiam na face externa do endopodito da zoea I são substituídas, no $2 .^{\circ}, 3^{\circ}$ e $4 .^{\circ}$ segmentos, por 1 longa cerda plumosa em cada um. $O$ exopodito possui 7 longas cerdas plumosas terminais.

Segundo Maxilípede (Fig. 10-II) com basipodito provido de 7 cerdas plumosas marginais. O endopodito com 2, 2, 1 e 5 cerdas plumosas, na face interna, do segmento proximal para o distal. As cerdas simples que existiam na face externa do $2 .^{\circ}$ e $3 .^{\circ}$ segmentos do endopodito da zoea I são substituídas por 1 longa cerda plumosa em cada um. O exopodito sustenta 7 cerdas plumosas terminais.

Terceiro Maxilípede (Fig. 11-II) com o endopodito bisegmentado, com 1 cerda simples terminal e o exopodito, também bisegmentado, com 5 cerdas plumosas no segmento distal.

\section{ZOEA III (Fig. 1-III a 11-III)}

Carapaça sub-retangular semelhante à da zoea II, mas com o par de espinhos ântero-laterais bem mais desenvolvido. Os olhos tornamse bem pedunculados. Os pleópodos exteriorizam-se, articulam-se nos segmentos abdominais e adquirem cerdas plumosas aistais. $O$ telso (Fig. 3-III) possui a fórmula $8+1+8$, pela adição de um processo ímpar mediano.

Antênula (Fig. 4-III) birreme, com pedúnculo segmentado. $O$ segmento distal sustenta 2 cerdas plumosas e 1 cerda simples. Endopodito com 1 cerda plumosa. Exopodito com 5 estetos, 1 cerda plumosa e 2 simples.

Antena (Fig. 5-III) com o aspecto geral semelhante ao do estágio anterior, exceção ao endopodito que é trisegmentado.

Mandíbula (Fig. 6-III) com a mesma forma geral do estágio anterior mas com o palpo mais desenvolvido.

Maxílula (Fig. 7-III) com o endopodito provido de 2 cerdas simples terminais. O endito basal apresenta 5 ou 6 pequenos espinhos e 2 cerdas simples. $O$ endito coxal possui 5 cerdas simples.

Maxila (Fig. 8-III) com 9 cerdas plumosas marginais no exopodito e apenas 1 cerda simples no endopodito. $O$ endito basal apresenta 0 lobo distal com 3 cerdas plumosas e o proximal com 2. O endito coxal possui 3 cerdas plumosas e 1 espinho no lobo proximal e 3 cerdas plumosas no lobo distal.

Primeiro Maxilípede (Fig. 9-III) com basipodito provido de 5 cerdas plumosas. Endopodito ccm, respectivamente, $1,1,1,2$ e 4 cerdas plumosas, na margem interna do $1 .^{\circ}$ ao $5 .^{\circ}$ segmentos. $02 .^{\circ}, 3 .^{\circ}$ e $4 .^{\circ}$ segmentos apresentam também 1 cerda plumosa na margem externa. O exopodito não sofre modificações em relação ao estágio anterior.

Segundo Maxilípede (Fig. 10-III) com basipodito provido de 5 cerdas plumosas. Endopodito com, respectivamente, $1,1,1$, e 5 cerdas plumosas, na margem interna, do $1 .^{\circ}$ ao $4 .^{\circ}$ segmentos, e 1 na margem externa do $3^{\circ}$. O exopodito não sofre modificações em relação ao estágio anterior.

Terceiro Maxilípede (Fig. 11-III) com o endopodito tetrasegmentado, provido de 1 cerda simples no $1 .^{\circ}$ e $4 .^{\circ}$ segmentos. Exopodito com 
6 cerdas plumosas.

Urópodo (Fig. 3-III) com o exopodito provido de 1 pequeno espinho terminal, e 7 ou 8 cerdas plumosas, em sua margem distal. $O$ endopodito é pequeno com sua margem distal lisa ou provida de 1 a 3 cerdas plumosas.

\section{MEGALOPA (Figs. 1-IV a 11-IV e 12)}

A carapaça com seus espinhos ântero-laterais e o rostro são nitidamente menores quando comparados com os dos estágios de zoea. $O$ rostro apresenta-se com o ápice arredondado. Os olhos são bem pedunculados. Não há escamas oculares. Os segmentos abdominais sofrem um encurtamento no sentido ântero-posterior e um alargamento lateral. O telso (Fig. 3-IV) é pentagonal e sustenta, na sua porção distal 9 cerdas plumosas.

Antênula (Fig. 4-IV) com o pedúnculo antenular trisegmentado, provido de algumas cerdas simples esparsas. O expodito é constituído por 4 segmentos, com os 3 primeiros curtos e $04^{\circ}$ alongado. Os 2 primeiros segmentos são lisos, o 3..$^{\circ}$ apresenta 3 cerdas simples e $04 .^{\circ}, 4$ cerdas simples e 6 estetos. O endopodito é bisegmentado com 2 cerdas simples no segmento proximal e 6 a 8 no distal.

Antena (Fig. 5-IV) com o pedúnculo antenal composto por quatro segmentos. $01 .^{\circ}$ e o $3 .^{\circ}$ segmentos sustentam 1 cerda simples, o $2 .^{\circ}$ é liso e o $4 .^{\circ}$ apresenta 1 espinho e 4 cerdas simples. $O$ exopodito (escama) é bem reduzido. $O$ flagelo antenal apresenta 5 segmentos com 0,2 , 7, 4 e 8 cerdas simples, do segmento proximal para o distal.

Mandíbula (Fig. 6-IV) com a forma geral semelhante à do adulto. Na região correspondente aos dentes cônicos, que existiam nas zoeas, surge a lâmina cortante. $O$ palpo é bisegmentado, com 7 cerdas simples no segmento distal.

Maxílula (Fig. 7-IV) com o endito basal provido de 5 pequenos espinhos e 11 cerdas simples. $O$ endito coxal apresenta 3 cerdas simples e o endopodito 2.

Maxila (Fig. 8-IV) com o exopodito provido de 28 cerdas plumosas marginais e 1 mediana. $O$ endopodito é liso. $O$ endito basal possui 5 cerdas simples no lobo distal e 4 no lobo proximal. O endito coxal apresenta 2 cerdas simples em cada lobo.

Primeiro Maxilípede (Fig. 9-IV) bastante modificado em relação aos dos estágios de zoea. 0 coxopodito possui 3 cerdas simples e o basipodito, 17. $O$ endopodito é liso e não segmentado. $O$ exopodito é bisegmentado, bastante reduzido, com apenas 1 cerda plumosa.

Segundo Maxilipede (Fig. 10-IV) com basipodito alargado provido de 3 cerdas simples. $O$ exopodito apresenta-se alongado e liso, com o segmento distal dobrado sobre o proximal. $O$ endopodito apresenta, respectivamente, 1, 0, 1 e 3 cerdas simples, do segmento proximal para 0 distal.

Terceiro Maxilípede (Fig. 11-IV) com basipodito provido de 2 cerdas simples. $O$ exopodito é reduzido, com apenas 2 cerdas simples terminais. Endopodito desenvolvido com, respectivamente, 5, 7, 8 e 7 cerdas simples, do segmento proximal para o distal. $O$ ísquio, que é fundido ao basipcdito, é provido de uma reduzida "crista dentata" composta por 2 pequenos dentes. 
Os Quelípodos (Fig. 12-Q) são simétricos, providos de pequenas cerdas simples em todos os segmentos além de pequenos espinhos no mero, carpo e própodo. O mero e o própodo são maiores que os demais segmentos. O comprimento do dátilo (dedo móvel) corresponde, aproximadamente à metade do comprimento da mão.

O Segundo e o Terceiro Pereiópodos (Fig. 12- $\mathrm{P}_{2}$ e 12- $\mathrm{P}_{3}$ ) são recobertos por pequenas cerdas simples esparsas. Ambos possuem o dátilo agudo e ligeiramente maior que o própodo.

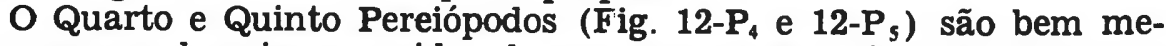
nores que os demais e providos de pequenas cerdas simples. $O$ quarto pereiópodo possui 5 grânulos córneos no própodo. $05 .^{\circ}$ pereiópodo possui 6 grânulos córneos no própodo e 3 no dátilo.

Os Pleópodos (Fig. 12-PL) são em número de 4 pares, inseridos no $2 .^{\circ}, 3^{\circ}, 4^{\circ}$ e $5^{\circ}$ somitos abdominais. Apresentam 8 cerdas plumosas no exopodito e 2 cerdas, em forma de gancho, no endopodito.

O Urópodo (Fig. 3-IV) apresenta o protopodito liso e o endopodito com 3 cerdas plumosas, 3 cerdas simples e 5 grânulos córneos. O exopodito possui 11 ou 12 cerdas plumosas e 9 ou 10 grânulos córneos.

\section{DISCUSSAO E CONCLUSÕES}

O fato de $\mathbf{P}$. tortugae ter uma metamorfose muito rápida, envolvendo apenas quatro dias para atingir a fase de megalopa, não foge à regra geral constatada para as outras seis espécies do gênero Paguristes, com desenvolvimento pós-embrionário conhecido.

Assim, P. abbreviatus já eclode na fase de megalopa, P. oculatus atinge: a fase de megalopa em apenas 20 a 30 horas, $\mathbf{P}$. turgidus em 5 dias, P. digitalis em 7 dias, $\mathbf{P}$. sericeus em 10 a 16 dias e P. spinipes em 23 dias. Comparativamente com os outros gêneros da família Diogenidae verifica-se que, de uma maneira geral, o tempo requerido para a obtenção da megalopa em Paguristes, é sempre inferior. Por outro lado, de acordo com Forest \& Saint Laurent (1967) e Provenzano (1978), o gênero Paguristes apresenta mais de uma centena de espécies, com uma distribuição geográfica muito ampla, em todos os mares tropicais e temperados quentes. Considerando-se a maior rapidez da metamorfose como uma possivel linha de especialização, pode-se atribuir a este fator a grande especiação que ocorre em Paguristes, sobrepujando, neste particular, os demais gêneros da família.

Analisando-se as descrições das zoeas das seis espécies do gênero Paguristes com metamorfose conhecida e incluindo-se agora $\mathbf{P}$. tortugae, verifica-se que independentemente do estágio considerado, as zoeas deste gênero diferem de todas as outras da família Diogenidae, por apresentarem um par de espinhos cómeos, localizados na região ântero-lateral da carapaça. A fase de megalopa deste gênero pode ser identificada simplesmente por dois caracteres tomados em conjunto, ou seja, presença de quelípodos simétricos e endopodito da antênula constituído por apenas dois segmentos.

O estudo anatômico comparativo entre as zoeas de P. tortugae e P. spinipes, a outra espécie brasileira com desenvolvimento pós-embrionário conhecido, evidencia que ambas são bastante próximas mas facil- 
mente identificáveis através de certas particularidades que ocorrem sobretudo nas antênulas, antenas, mandíbulas e terceiros maxilípedes, apresentados na tabela I.

Na fase de megalopa, a distinção entre P. tortuge e P. spinipes pode ser obtida pela simples contagem das cerdas plumosas dos endopoditos dos urópodos. Assim enquanto em P. tortugae ocorre apenas 3 cerdas plumosas na mencionada estrutura, em P. spinipes existe 9 a 14. Acrescente-se ainda, que as megalopas de $\mathbf{P}$. tortugae tem um comprimento total de $1,8 \mathrm{~mm}$ e $\mathbf{P}$. spinipes de $3,8 \mathrm{~mm}$.

\section{AGRADECIMENTOS}

Ao Conselho Nacional de Desenvolvimento Científico e Tecnológico (CNPQ), pelo financiamento da presente pesquisa.

\section{REFERENCIAS BIBLIOGRAFICAS}

BROSSI-GARCIA, A. L. 1979. Desenvolvimento pós-embrionário de Clibanarius antillensis Stimpson, 1859 e Pagurus criniticornis (Dana, 1852) (Crustacea, Paguridea). UNESP - Campus de Rio Claro. Tese de Mestrado. 97 pp.

DECHANCE, M. 1963 - Développment direct dez un paguride, Paguristes abbreviatus Dechancé, et remarques sur le dévelopment des Paguristes. Bull. Mus. Nat. Paris, 2.a série 35(5): 488-495.

FOREST, J. \& M. SAINT LAURENT 1967. Campag ne de la "Calypso" au large des côtes Atlantiques de l'Amérique du Sud (1961-1962). 6. Crustacés Décapodes: Pagurides. Ann. Inst. Océanogr. Monaco, 45(2) : 47-169.

GURNEY, R. 1942 - Larvae of Decapod Crustacea. Ray. Soc. London, 129: 1-306.

HART, J. F. L. 1937 - Larval and adult stages of British Columbia Anomura. Natl. Res. Coun. Canada, 15(10): 179-220.

KAESTNER, A. 1970 - Invertebrate Zoology. III Crustacea. Interscience Publishers, London, $523 \mathrm{p}$.

KURATA, H. 1968 - Larvae of Anomura of Arasaki Sagami Bay. III. Paguristes digitalis (Stimpson) (Dicgenidae). Bull. Tokai Reg. Fish. Res. Lab., 56: 181186.

LANG, W. H. \& A. M. YOUNG 1977 - The larval development of Clibanarius vittatus (Bosc) (Crustacea: Decapoda: Dicgenidae) reared in the laboratory. Biol. Bull., 152: 84-104.

MACDONALD, J. D.; R. B. PIKE \& D. I. WILLIAMSON 1957 - Larvae of the British species of Diogenes, Pagurus, Anapagurus and Lithodes (Crustacea, Decapoda). Proc. Zool. Soc. London, 128 (2) : 209-257.

PIKE, R. B. \& D. I. WILLIAMSON 1960 - Larvae of decapod Crustacea of the families Dicgenidae and Faguridae from the Bay of Naples. Pubbl. Staz. Zool. Napoli, 31: 493-552.

PROVENZANO JR., A. J. 1962 - The larval development of Ca'cinus tibicen (Herbst) (Crustacea, Anomura) in the laboratory. Biol. Bull., 123(1): 179-202.

PROVENZANO JR., A. J. 1968 - The complete larval development of the west Indian hermit crab Petrochirus dicgenes (L.) (Decapoda, Diogenidae) reared in the laboratory. Bull. Mar. Sci., 18(1): 143-181.

PROVENZANO JR., A. J. 1978 - Larval development of the hermit crab Paguristes spinipes Milne-Edwards. 1880 (Decapoda, Diogenidae) reared in the laboratory. Bull. Mar. Sci., $28(3)$ : 512-526.

RICE, A. L. \& A. J. PROVENZANO JR. 1965 - The zoeal stages and the glaucothöe of Paguristes sericeus Milne-Edwards (Anomura, Diogenidae) (Crustaceana 8(3): $239-254$.

SCELZO, M. A. \& E. E. BOSCHI 1969 - Desarrollo larval del cangrejo hermitãno Pagurus exilis (Benedict) en laboratorio (Crustacea, Anomura, Paguridae). Physis Tomo XXIX (78): 165-184. 

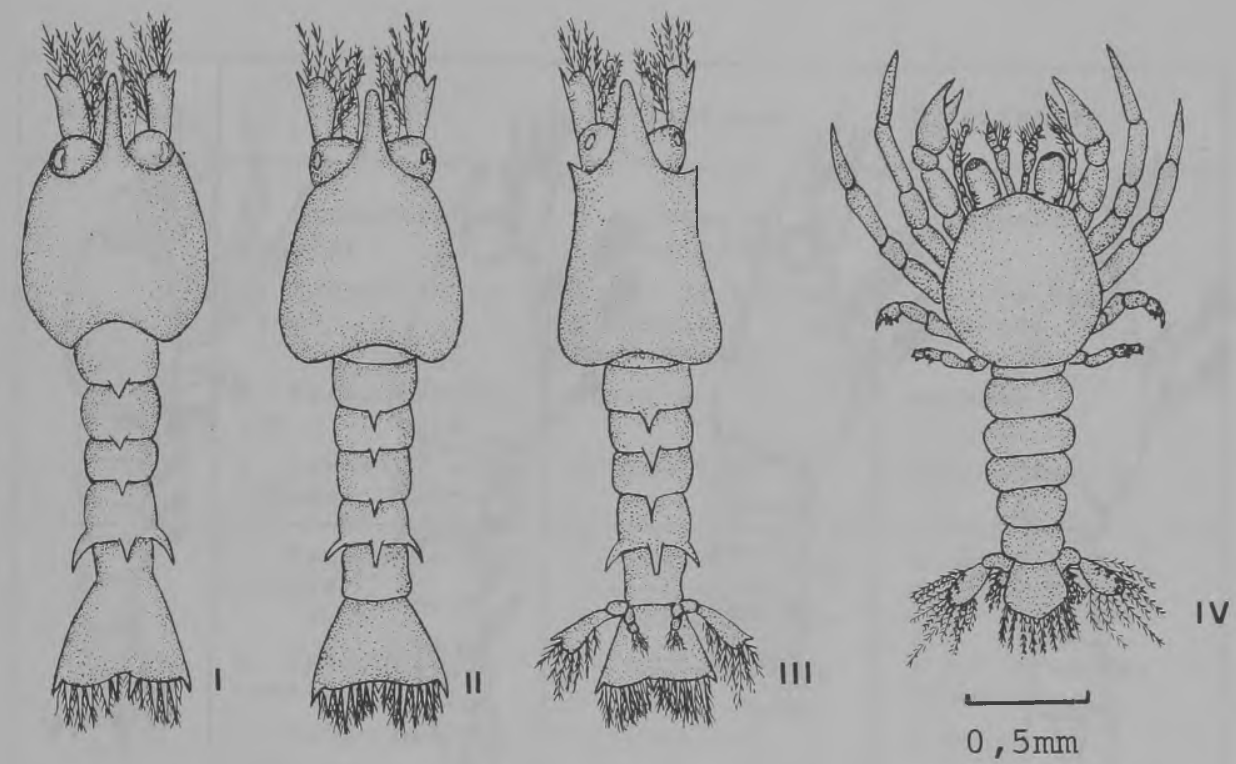

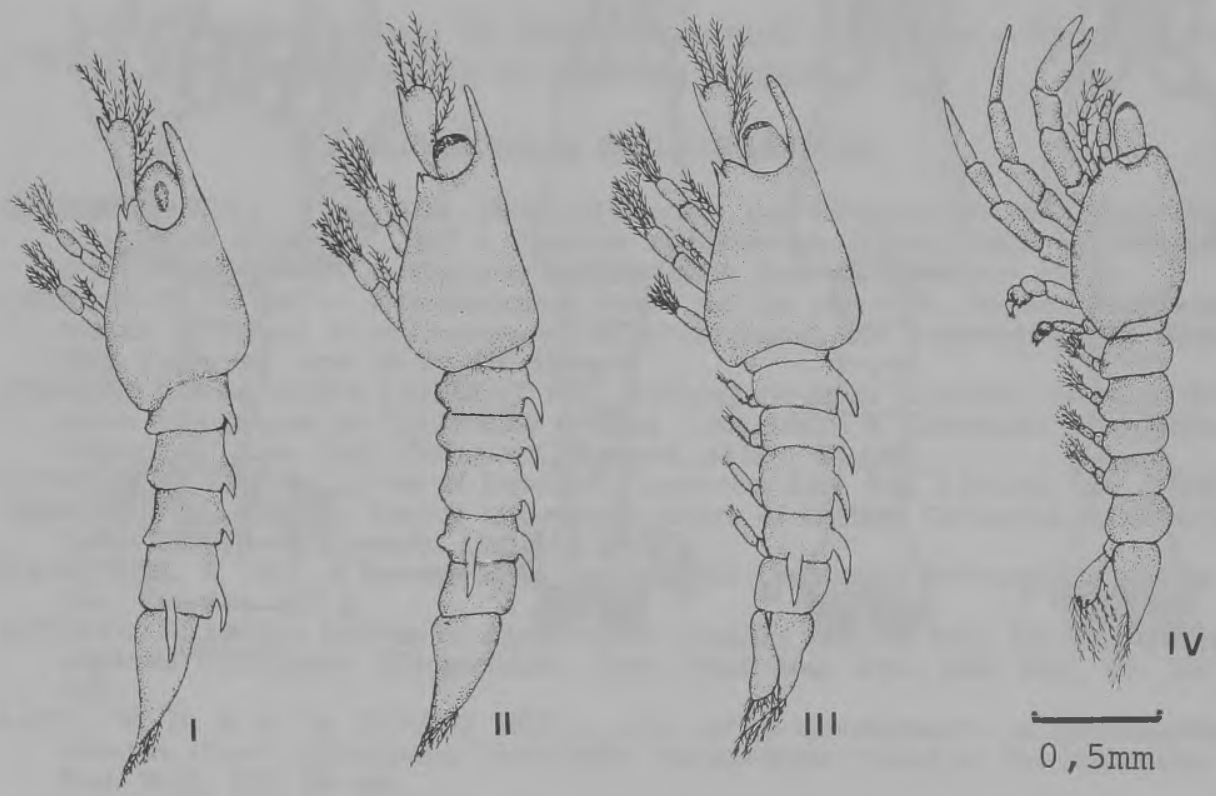


\begin{tabular}{|c|c|c|c|}
\hline Estāgio & & P. tortugae & P. spinipes \\
\hline ZOEA I & $\begin{array}{l}\text { 1. Exopodito an- } \\
\text { tenular } \\
\text { 2. Exopodito an- } \\
\text { tenal } \\
\text { 3. Palpo mandibu } \\
\text { lar } \\
\text { 4. Terceiro maxí } \\
\text { lipede }\end{array}$ & $\begin{array}{l}3 \text { estetas e } 3 \\
\text { cerdas plumosas } \\
\text { ll ou } 12 \text { cerdas } \\
\text { plumosas e l cer } \\
\text { da simples. } \\
\text { ausente } \\
\text { rudimentar }\end{array}$ & $\begin{array}{l}5 \text { estetas } \\
9 \text { ou } 10 \text { cerdas } \\
\text { plumosas } \\
\text { ausente } \\
\text { rudimentar }\end{array}$ \\
\hline ZDEA II & $\begin{array}{l}\text { 1. Exopodito an- } \\
\text { tenular } \\
\text { 2. Exopodito an- } \\
\text { tenal } \\
\text { 3. Palpo mandibu } \\
\text { lar } \\
\text { 4. Exopodito do } \\
\text { terceiro maxilí- } \\
\text { pede }\end{array}$ & $\begin{array}{l}3 \text { estetas, } 3 \text { cer } \\
\text { das plumosas e } \\
2 \text { cerdas simples } \\
11 \text { cerdas plumo } \\
\text { sas } \\
\text { rudimentar } \\
5 \text { cerdas plumo- } \\
\text { sas }\end{array}$ & $\begin{array}{l}5 \text { estetas e } 2 \\
\text { cerdas plumo- } \\
\text { sas } \\
9 \text { ou } 10 \text { cerdas } \\
\text { plumosas } \\
\text { ausente } \\
6 \text { ou } 7 \text { cerdas } \\
\text { plumosas }\end{array}$ \\
\hline ZDEA I I I & $\begin{array}{l}\text { 1. Exopodito an- } \\
\text { tenular } \\
\text { 2. Exopodito an- } \\
\text { tenal } \\
\text { 3. Palpo mandibu } \\
\text { lar } \\
\text { 4. Terceiro maxi } \\
\text { lipede: } \\
\text { Exopodito com: } \\
\text { Endopodito com: }\end{array}$ & $\begin{array}{l}5 \text { estetas, cer } \\
\text { da plumosa e } \frac{}{2} \\
\text { simples } \\
\text { ll cerdas plumo } \\
\text { sas } \\
\text { bem desenvolvi- } \\
\text { do } \\
6 \text { cerd.plumosas } \\
2 \text { cerd. simples }\end{array}$ & $\begin{array}{l}5 \text { ou } 6 \text { estetas } \\
\text { e } 2 \text { cerdas plu } \\
\text { mosas } \\
9 \text { ou } 10 \text { cerdas } \\
\text { plumosas } \\
\text { ausente }\end{array}$ \\
\hline
\end{tabular}



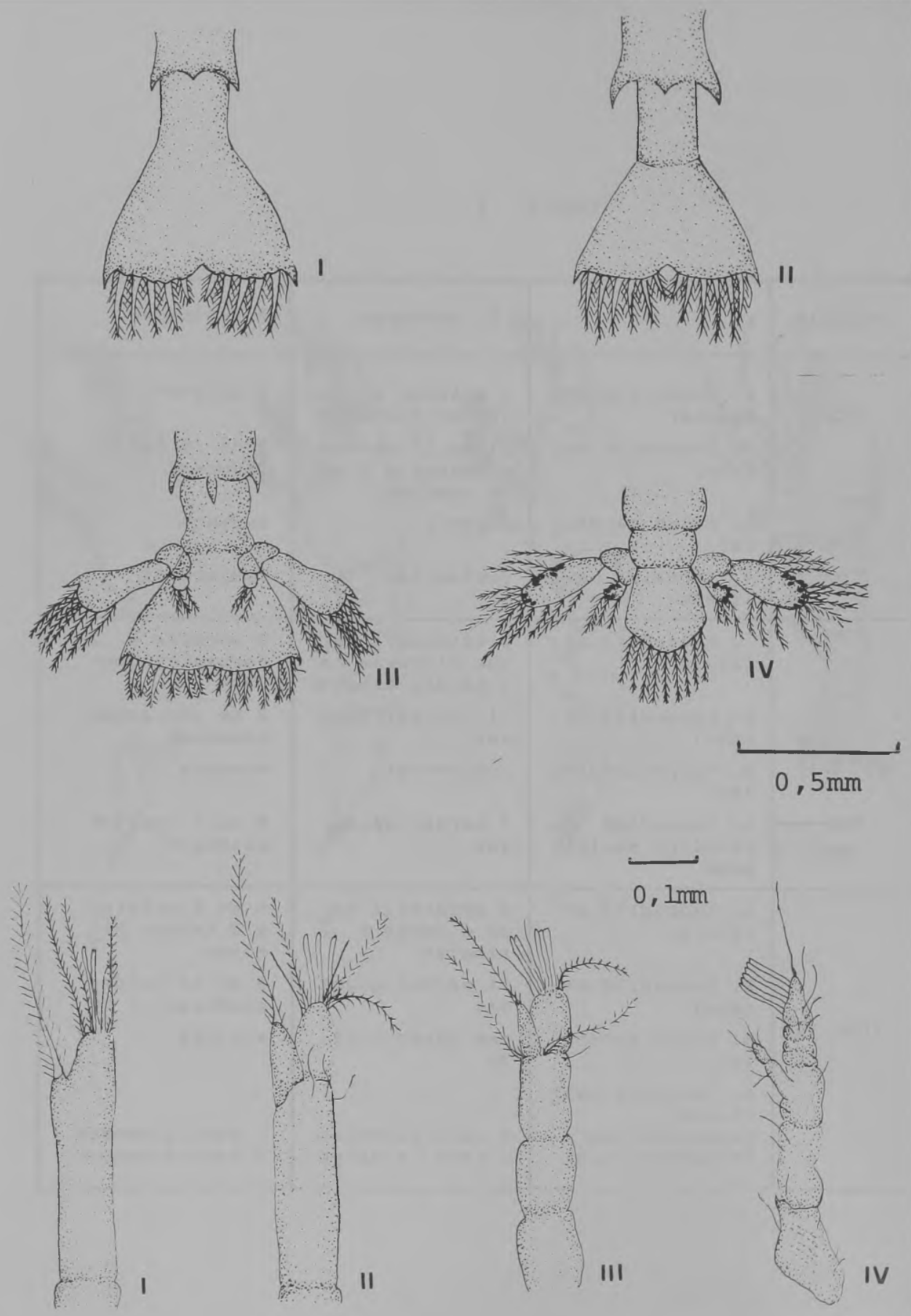


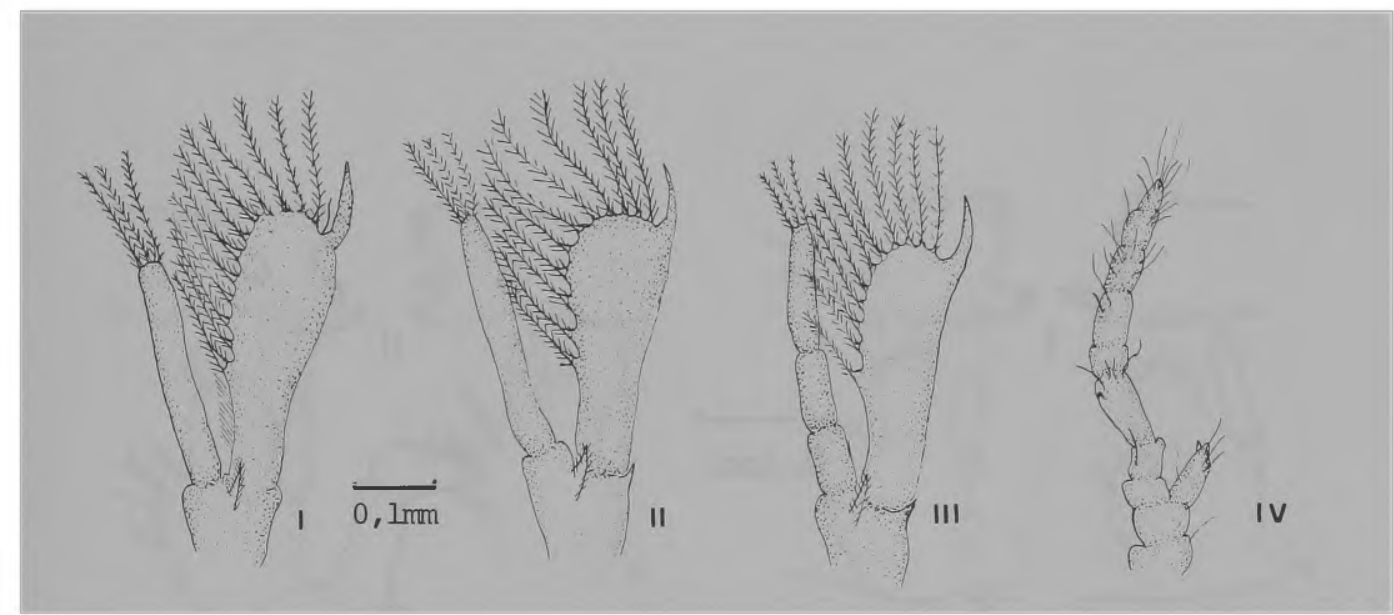



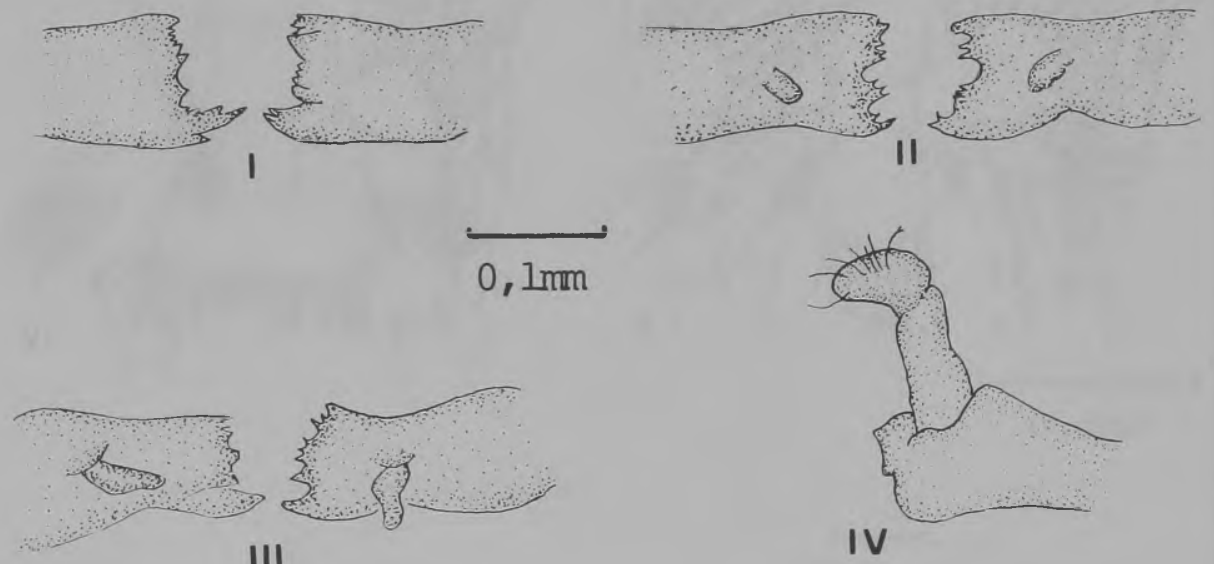


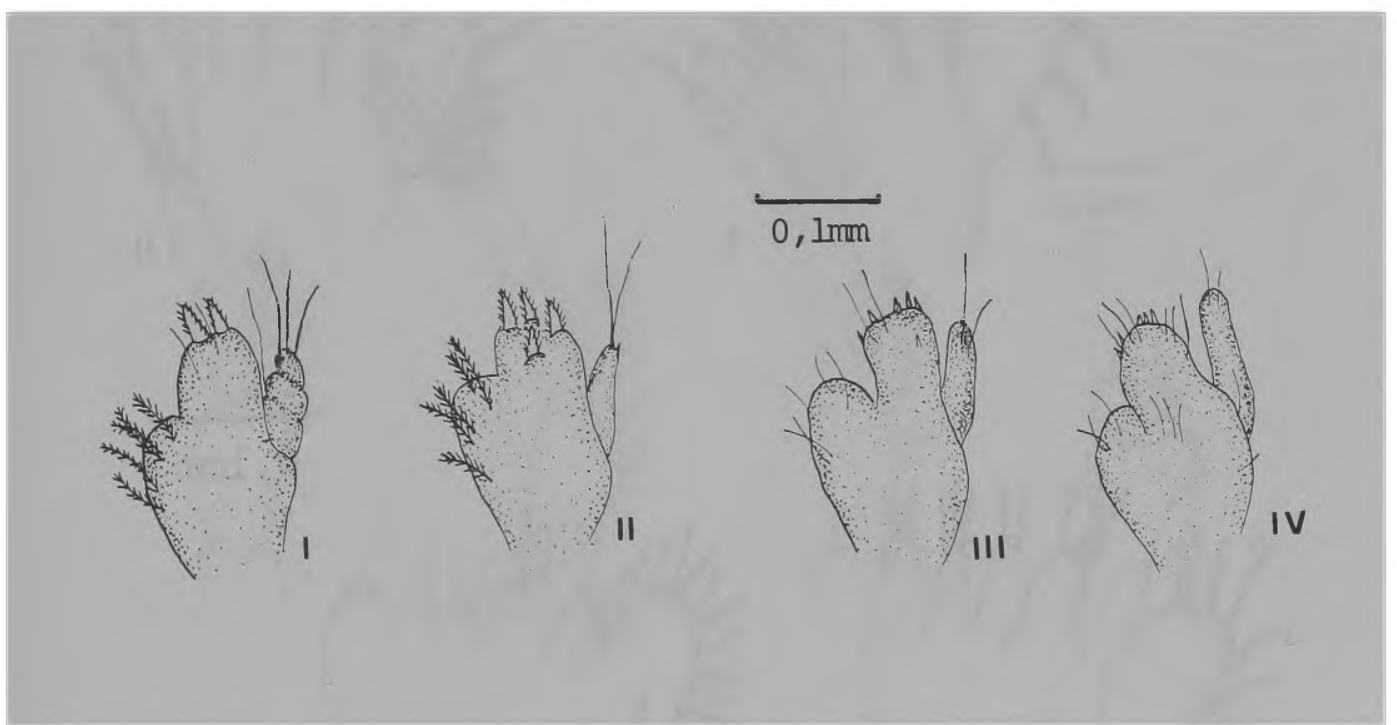



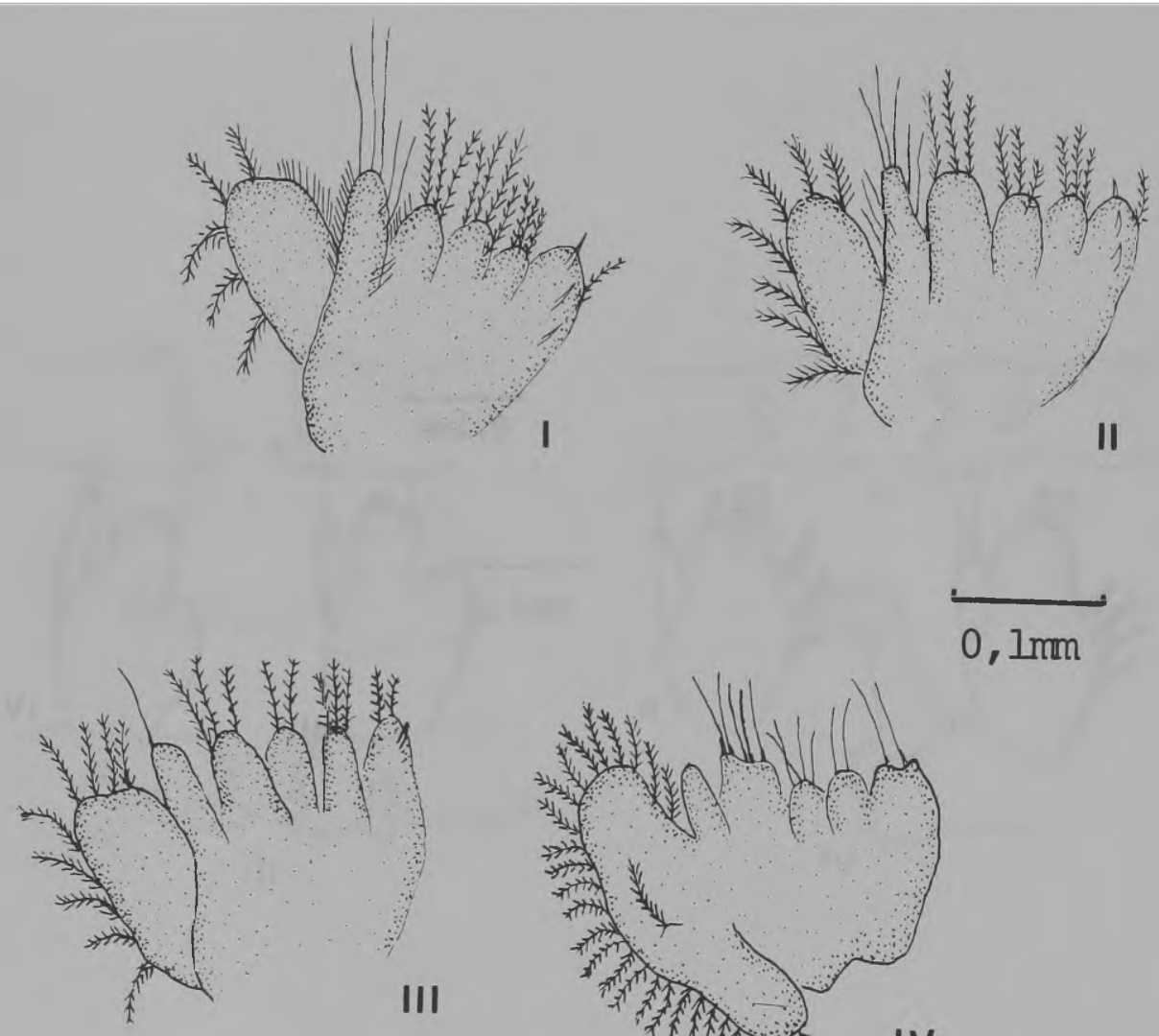


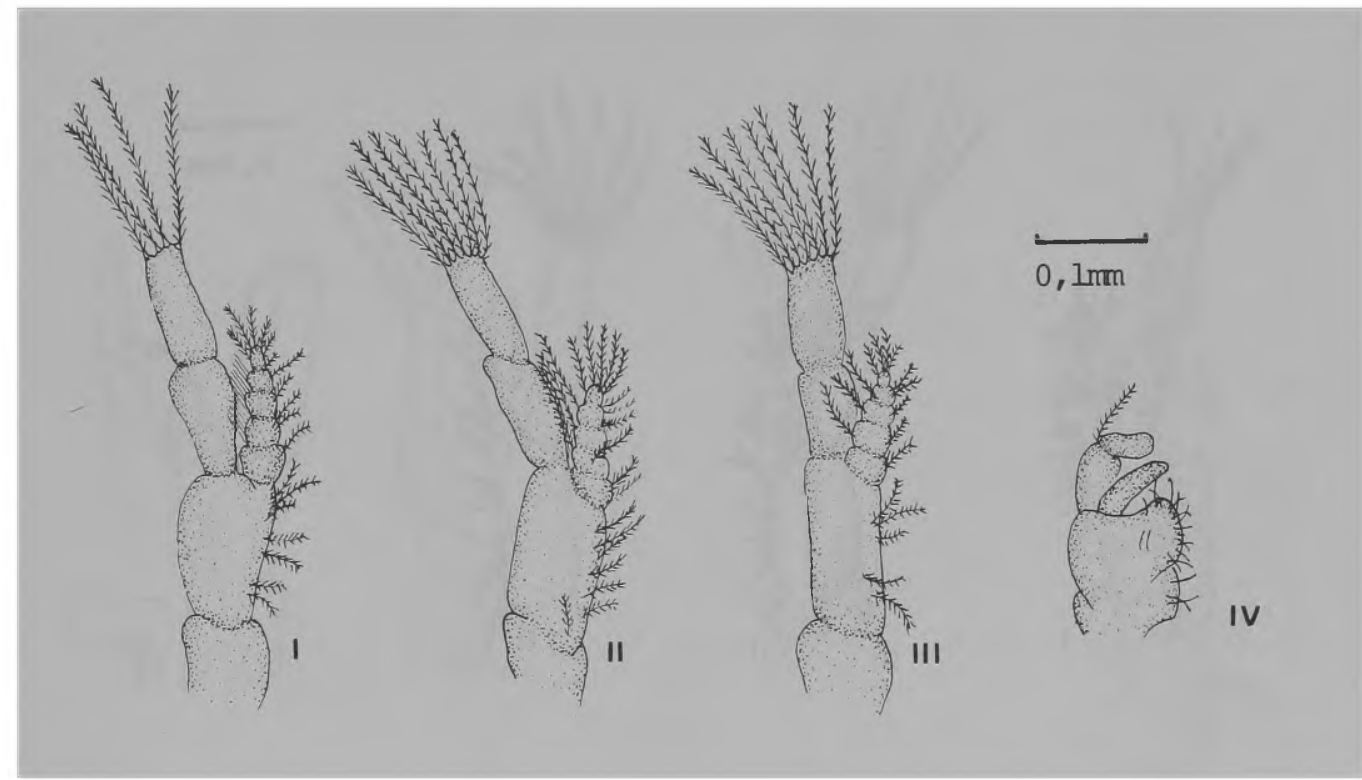



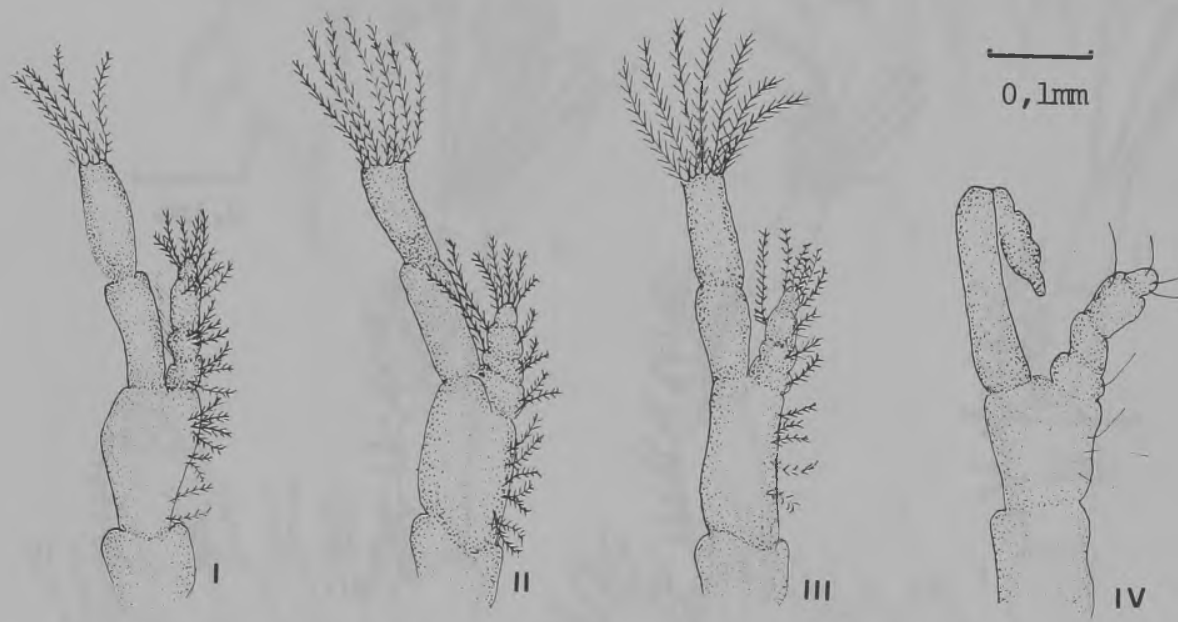


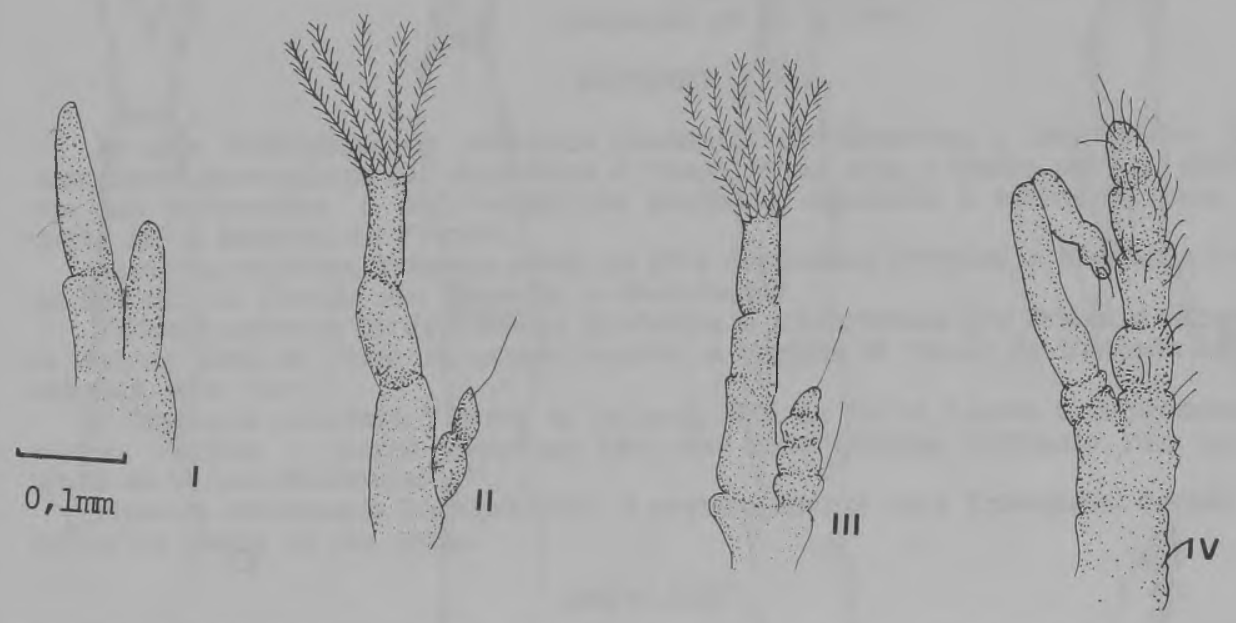



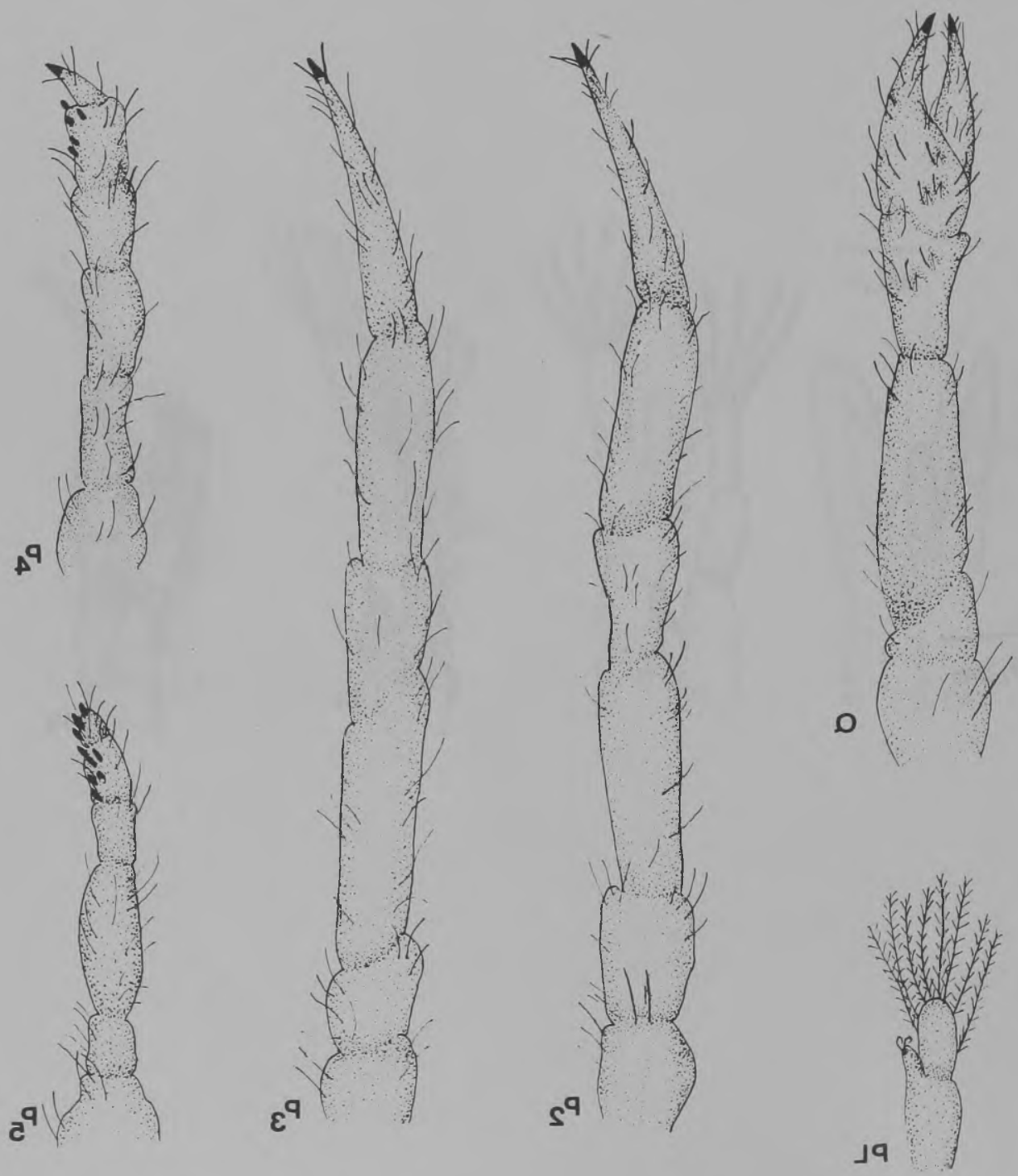

mा 10 